\title{
OS DEZ ANOS DA LEI No 11.645/2008: AVANÇOS E DESAFIOS
}

\author{
Francisca Navantino P. de Angelo (Chiquinha Paresi) ${ }^{1}$ (1)
}

RESUMO: Este artigo analisa os dez anos da Lei no 11.645/2008, que instituiu a obrigatoriedade do ensino de História e culturas indígenas nas escolas públicas e privadas. $\mathrm{O}$ foco está em como a lei tem sido instituída, os avanços e desafios da temática no âmbito das escolas públicas, nas universidades e centros de formação do estado do Mato Grosso. Apresenta aspectos da Resolução Normativa no 001/2013 do Conselho Estadual de Educação do Mato Grosso, que nos últimos anos propôs açóes de implementaçáo da Lei no $11.645 / 2008$ no estado. Analisa igualmente como a temática indígena tem sido acolhida nos currículos dos cursos da Universidade do Estado de Mato Grosso e da Universidade Federal de Mato Grosso.

Palavras-chave: Lei $\mathrm{n}^{\circ}$ 11.645. Escolas do sistema de ensino. Formaçáo de professores.

\section{0 years of Law No. 11,645/08: advances and challenges}

ABSTRACT: This article analyzes the 10 years of Law $11.645 / 08$, which established the obligation of teaching History and indigenous culture in public and private schools. The main objective of this paper is to show how the law has been established, the progress and challenges of this issue in the context of public schools, universities and training centers in the state of Mato Grosso. I present aspects of Normative Resolution

${ }^{1}$ Universidade do Estado de Mato Grosso - Mato Grosso (MT), Brasil.

DOI: $10.1590 / C C 0101-32622019216733$ 
No. 001/2003/CEE-MT, which in recent years proposed actions for the implementation of Law 11.645 in the state. The way how indigenous issues have been accepted in the curricula of the courses of the Mato Grosso universities was also analyzed.

Keywords: Law No. 11.645. Educational system schools. Teacher training.

\section{INTRODUÇÃO}

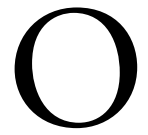

estado do Mato Grosso concentra um mosaico de diversidades étnicas, culturais e linguísticas, destacando-se como o segundo estado com o maior número de povos originários. Sáo 43 etnias que habitam tradicionalmente o território com diferentes línguas e tradiçôes. Nos primórdios da ocupação dos territórios indígenas pelos colonizadores/invasores ocorreram guerras, massacres, desaparecimento étnico e perseguiçóes que desencadearam diferentes processos de relaçóes conflituosas e interculturais com a sociedade colonizadora (CARNEIRO DA CUNHA, 2009; FREIRE, 2011). Cerezer (2015), sobre a colonização mato-grossense, aponta:

Os traços do passado histórico estão presentes em todas as instâncias da sociedade mato-grossense, incluindo as relaçôes raciais e a herança dela decorrente, como o racismo e a discriminação racial, elementos presentes e atuantes nessa sociedade. A permanência dessa realidade demonstra que os conflitos raciais construídos e sedimentados ao longo do processo histórico fincaram raízes profundas na sociedade mato-grossense e brasileira transformando os povos indígenas e a população negra nas principais vítimas (CEREZER, 2015, p. 44).

O advento da Lei $\mathrm{n}^{\circ}$ 11.645/2008 (BRASIL, 2004; 2008), que promulga a obrigatoriedade sobre história e culturas indígenas nas escolas públicas nos níveis da educação básica, é uma novidade para os 
sistemas de ensino no Brasil. A reparação histórica e cultural requer um intenso debate, discussóes e reflexóes, tanto na cultura brasileira quanto nos contextos acadêmicos, enfatizando a valorização da contribuição indígena (LUCIANO, 2006). Isso porque no imaginário da população mato-grossense e na brasileira como um todo a existência indígena está centrada em um passado remoto, mesmo após a promulgação da Constituição Federal de 1988 e seu capítulo específico dedicado aos povos indígenas (BRASIL, 1988). Argumento que existem variaçóes no entendimento e na aplicação das leis sobre escolarização indígena de acordo com a região ${ }^{1}$. É sobre essas variaçóes que vou me debruçar.

A temática indígena, no contexto da educação escolar matogrossense, foi pouco evidenciada como conteúdo para as áreas da educação básica. A lei é frequentemente exaltada no Dia do Índio, 19 de abril, quando as escolas desenvolvem atividades relacionadas ao tema, palestras, danças e atividades culturais ${ }^{2}$. A lei foi regulamentada apenas em 2013 no cenário educacional do estado. O Conselho Estadual de Educaçáo Escolar Indígena $^{3}$ (CEEI), na sua função de controle social, apresentou ao Conselho Estadual de Educação do Mato Grosso (CEE-MT) ${ }^{4}$ a proposta de criar um grupo de trabalho (GT) para regulamentar a Lei no $10.639 / 2003$ e a Lei $n^{\circ} 11.645 / 2008$ nos sistemas de ensino.

O reconhecimento da existência do preconceito, da discriminação e do racismo contra os povos indígenas no estado ficou evidenciado pelos seus relatos e pela resistência das escolas públicas em atender alunos indígenas que viviam em contexto urbano (LOURENÇO, 2017a; LUCIANO, 2006).

Com o trabalho do GT no interior do Conselho Estadual de Educação Escolar (CEE), a temática indígena foi trabalhada em conjunto com o CEEI, cujos membros dos GTs e a equipe técnica debateram a relevância da obrigatoriedade do ensino indígena em diferentes instâncias. No decorrer do processo, a tônica decisiva para o encaminhamento da aplicabilidade da lei referenciava a capacitação e a formação continuada dos profissionais da educação.

O presente artigo se baseia, portanto, nos dados coletados e analisados à luz da Lei no $11.645 / 2008$ e sua implementação no estado do Mato Grosso. No primeiro momento, os resultados foram coletados 
no sistema educacional, juntamente à equipe coordenadora. Para essa finalidade, alguns questionamentos foram feitos à equipe de profissionais que estava à frente do trabalho pedagógico. Eis as principais questóes: quais foram os processos demandados para se implementar a nova lei? De que forma as açóes foram desenvolvidas nos aspectos pedagógicos, curriculares e nas atividades escolares? Quais as estratégias de monitoramento e acompanhamento junto às escolas? Quantos materiais didáticos serão oferecidos aos profissionais sobre a temática indígena?

As respostas para essas questóes foram dadas por membros da equipe da Superintendência de Políticas de Diversidades Educacionais (SUDE) e da Secretaria de Estado de Educação, Esporte e Lazer (SEDUC), que me apresentaram um plano de trabalho e as diretrizes de dispositivos que orientaram as escolas da rede pública de forma geral. A segunda parte dos dados é referente às universidades públicas, especificamente a Universidade do Estado de Mato Grosso (UNEMAT) e a Universidade Federal de Mato Grosso (UFMT). Nesse contexto, uma das fontes que nos sustenta foi a tese de doutorado do professor pesquisador Osvaldo Mariotto Cerezer $^{5}$ (2015, p. 9), "resultante de uma pesquisa que teve como objetivo analisar a implementação das leis 10.639/03 e 11.645/08 na educação básica”. A temática indígena em pauta nas universidades públicas atende à lei nos componentes curriculares dos cursos de licenciatura em História para professores que atuam na educação básica.

A Lei no 11.645/2008 alavancou no estado, nesse sentido, após a aprovação e promulgação pelo CEE-MT e pela Resolução Normativa no 001/2013 (MATO GROSSO, 2013). Em 2014 a SEDUC, através da $\mathrm{SUDE}^{6}$, propôs como estratégia produzir a capacitação dos formadores de 15 polos do Centro de Formação e Atualização dos Profissionais da Educação $(\mathrm{CEFRAPO})^{7}$ e, desse modo, inclui-os como multiplicadores de açóes inseridas no plano de trabalho anual, abrangendo diferentes setores e unidades escolares. As unidades escolares somam, particularmente, 720 unidades, distribuídas nos 141 municípios do Mato Grosso.

É nesse contexto institucional, portanto, que a Resolução no $001 / 2013$, que dispóe sobre a oferta obrigatória da educação das relaçóes étnico-raciais e do estudo da história e cultura afro-brasileira, africana e indígena nos estabelecimentos da educação básica, vem se instituindo no estado (MATO GROSSO, 2013). 


\section{A IMPLEMENTAÇÃO E SEUS DESDOBRAMENTOS NAS ESCOLAS DO MATO GROSSO}

Com a Resoluçâo Normativa no 001/2013, a Lei no $11.645 / 2008$ foi regulamentada, propondo que as escolas públicas inserissem nos seus projetos político-pedagógicos (PPPs) a temática indígena. Para esse fim, foi elaborado um conjunto de orientações técnicas e pedagógicas com o objetivo de implementar e assegurar o envolvimento dos profissionais da educação básica. É nesse contexto que passo a citar os dispositivos orientativos e as diretrizes para o sistema de ensino do Mato Grosso.

Além do Parecer Orientativo sobre a aplicabilidade da Resolução Normativa no 001/2013 (MATO GROSSO, 2013), aqui já mencionado, outro dispositivo legal emitido pela SEDUC foi o Orientativo para a Reformulação do PPP/2017 (SEDUC, 2017) e a escolha do livro anual didático. $\mathrm{O}$ segundo documento preconiza que as unidades escolares, ao realizarem a reformulação de seus PPPs, devem atender aos seguintes dispositivos legais:

I - A Constituição Federal de 1988;

II - Lei Federal no 9.394/1996, em seu artigo 26 (Alterado pela Base Nacional Comum Curricular 12.796/2013, Art. $3^{\circ}$, inciso XII - consideração com a diversidade étnico racial);

III - Lei Federal no 10.639/2003 (Plano Nacional de Implementação das Diretrizes Curriculares Nacionais para a Educação das Relaçôes Étnico-Raciais e para o Ensino de História e Cultura Afro-Brasileira e Africana);

IV - Lei 11.645/2008 (que trata da obrigatoriedade da História e cultura africana, afro-brasileira e indígena em todo o currículo escolar);

V - O Plano Nacional de Implementação das Diretrizes Curriculares de Educação as Relaçôes Étnico-Raciais 
e para o Ensino de História e Cultura Africana e Afro-Brasileira (2009; 2013);

VI-OPlano Estadual deEducação de Mato Grosso-2014 (meta 02, estratégia 13 - assegurar o desenvolvimento de projetos curriculares articulados com a base nacional comum, relacionados à educação ambiental, à educação das relaçôes étnico-raciais e dos direitos humanos, gêneros, sexualidade e música) (SEDUC, 2017).

Os instrumentos citados constituem documentos institucionais que fundamentam a aplicabilidade da lei no estado e são, propriamente, parte de um conjunto de diretrizes que compóem a referida Resolução Normativa no 001/2013 (MATO GROSSO, 2013). Os instrumentos funcionam como um complemento obrigatório às açóes a serem inseridas nos PPPs das escolas do Mato Grosso. Na continuidade do mesmo dispositivo, a Nota Técnica no 9/2015 expressa:

a) Currículo do Ensino Fundamental, Médio e modalidades;

b) A (re) elaboração dos Projetos Políticos Pedagógicos deverá apresentar as estratégias e metodologias de implementação das Leis 10.639/03 e 11.645/08;

c) O Plano de Ação Bienal e Anual do PPP deverá conter, no mínimo, $10 \%$ de recursos destinados à açáo de implementação das Leis 10.639/03 e 11.645/08;

d) As discussôes na Sala do Educador deverão obrigatoriamente contemplar estudos referentes às Leis $10.639 / 03$ e $11.645 / 08$;

e) O monitoramento da aplicabilidade deste orientativo será da Equipe de Assessoramento Técnico da Superintendência de Diversidades Educacionais e Equipe de Assessores Pedagógicos da Superintendência da Educação Básica (apud SEDUC, 2017, p. 3). 
Cada documento fortalece a finalidade do processo de aplicabilidade e coloca em discussão a trajetória histórica e cultural dos povos indígenas nos contextos contemporâneos, conforme o Parecer Orientativo (MATO GROSSO, 2013, p. 1):

As orientaçóes pedagógicas para se trabalhar a temática indígena se consubstanciam no reconhecimento e valorização das matrizes indígenas na cultura brasileira, juntamente com a africana, europeia e asiática, bem como na reparação histórica diante das atrocidades ocorridas na construção do país e na necessidade de revisão da historiografia do Brasil e de Mato Grosso.

Para que essa importante proposição fosse mais efetiva, tivesse visibilidade e acolhesse a diversidade sociocultural proporcionando a formação continuada dos profissionais da educação, a equipe da Secretaria de Educaçáo do Mato Grosso produziu um planejamento de como o trabalho deveria ser implementado, priorizando inicialmente a participação dos profissionais da educação que atuam na primeira etapa da educação básica, especificamente na região do Vale do Rio Cuiabá, que compóe um complexo de vários municípios da Baixada Cuiabana. Outra ação realizada foi um monitoramento por amostragem, em parceria com o Centro de Formação e Atualização dos Profissionais da Educação (CEFAPRO), assessorias pedagógicas e unidades escolares.

Para a execução de tal objetivo, no programa da equipe da SUDE, por exemplo, consta o aproveitamento da Caravana da Diversidade $^{8}$, criada em maio de 2017, com carga horária de quatro horas. Trata-se de um programa de governo que percorreu a regiáo do Vale do Rio Cuiabá com equipes multidisciplinares prestando atendimento social e jurídico à população nos municípios. Outra ação importante compreendeu o curso Métodos e Práticas Educativas em Direitos Humanos, cujo objetivo é "abordar a diversidade étnico-racial, indígena, sexual e de gênero dentro do ambiente escolar" (LOURENÇO, 2017a, p. 9). Nesse sentido, o objetivo foi difundir e valorizar não apenas a temática da história e culturas indígenas do Mato Grosso, mas dar subsídios teóricos 
e pedagógicos aos 60 "formadores - multiplicadores" da rede estadual CEFAPRO em todos os polos (com carga horária de 30 horas), incluindo ainda 30 professores de Cuiabá e Várgea Grande que concentram formação no campo de Antropologia.

As demais regióes do estado ficaram sob a responsabilidade das assessorias pedagógicas; e quando necessário a equipe da SUDE/SEDUC acompanha os projetos nos municípios em seus polos específicos. É a partir de tais trabalhos, em suma, que se amparam as açóes que atendem à Resolução Normativa no 001/2013 (MATO GROSSO, 2013).

O CEFAPRO de Barra do Garças, por exemplo, tem avançado nas ações para formação de profissionais e alcançado uma rede articuladora em Cuiabá. Vale destacar como assuntos cruciais para o conteúdo programático dos cursos de formação continuada os tópicos relacionados ao tema do ensino intercultural, entre eles: a introdução à Lei no 11.645/2008; etnocentrismo e relativismo; perspectiva antropológica sobre a diversidade étnica e cultural dos povos indígenas no Brasil; identidades, fronteiras e relaçóes interétnicas; povos indígenas e o estado, entre outros conteúdos relativos às questôes indígenas em Cuiabá. Todos incluídos no conteúdo programático dos cursos de formação profissional.

Nos anos de 2008 a 2010 foi publicado, como fruto desses projetos de formação, o livro Orientaçóes Curriculares das Diversidades Educacionais, que subsidia o trabalho pedagógico dos professores do Mato Grosso (SEDUC, 2010). Apresentam-se concepçóes sobre a Filosofia e princípios como a promoção dos direitos humanos. O material se encontra amplamente divulgado nas escolas do estado. Cabe ainda destacar o Projeto de Monitoramento do Cumprimento das Leis Federais no 10.639/03 e no $11.645 / 08$, cujo público-alvo são professores, técnicos e gestores das escolas estaduais. Para tanto, a SEDUC prevê o seguinte monitoramento:

Fazer levantamento de dados no que tange à aplicabilidade das Leis Federais nas escolas da rede estadual de ensino, bem como orientar aqueles que ainda não praticam uma educação pautada nos Direitos da Pessoa Humana. O objetivo do projeto é a análise dos dados coletados durante as visitas técnicas para posterior produção de artigo científico (SEDUC, 2017, p. 9). 
Passando para a análise das universidades, o ponto que destaco são as iniciativas realizadas por docentes, pesquisadores e alunos da pós-graduação sobre a temática indígena nas áreas de Educação e Antropologia da UFMT. Destaco a parceria realizada em 2018, entre a UFMT (particularmente o Departamento de Antropologia, História e o Museu de Etnologia e Arqueologia - MUSEAR/UFMT) e a SEDUC/SUDE. Juntas, as instituiçóes criaram um projeto voltado para discutir a diversidade sociocultural e linguística dos povos indígenas. Trata-se do "Curso Formação Intercâmbio Educacional e Intercultural - A Lei 11.645/08 em suas dimensões pedagógicas”. A ação capacitou profissionais da educação, atuantes na educação básica do sistema estadual. Assim, buscou-se formar "cidadãos críticos, emancipados, criativos, cuidadosos e conscientes de seus direitos, bem como dos direitos daqueles que estáo à sua volta. Tudo isso demanda profissionais da educação capacitados para gerenciar ações" (LOURENÇO, 2017 b, p. 23). Para a coordenadora do projeto, a proposta

se mostra pertinente por prestar subsídio teórico e pedagógico aos profissionais da Educação. Cabe a esses professores fomentar o diálogo com as escolas estaduais e municipais em que são lotados, tornando-se multiplicadores dos conteúdos oferecidos na formação. Esta ação visa oferecer um olhar aprofundado sobre a temática, troca de saberes, estudos de referencial teórico no sentido de auxiliar o trabalho com a diversidade étnica, cultural e linguística dos povos indígenas do estado de Mato Grosso no ambiente escolar para fomentar a execuçáo da Lei 11.645/08 (LOURENÇO, 2017b, p. 26).

O curso está voltado para um público diverso, com foco nos professores da educação básica das redes estaduais e municipais de ensino, além de estudantes do curso de Ciências Sociais e licenciaturas da UFMT. São oferecidas 100 vagas para as instituiçóes estaduais, 100 para as municipais e 15 aos discentes da universidade.

Outro aspecto que merece ser mencionado é a composição da equipe, formada por docentes da UFMT e estudantes indígenas. 
O curso, em 2018, contou com a participação dos indígenas: Eric Timoteo (Iwyrâkâ Kamikiawa), pertencente à etnia Kurâ-Bakairi, graduando do curso de Ciências Sociais e que participa do Programa de Inclusão Indígena (PROIND); e Maria Elizandra Lopes (Torekureuda), do povo Boe, mais conhecido como Bororo. Maria Torekureuda, formada em Psicologia, atualmente cursa o mestrado em Antropologia Social pela UFMT.

Entendo que essas iniciativas institucionais contribuirão, em médio e longo prazos, para a formação continuada dos profissionais para a inserção da temática indígena nos PPPs das escolas, superando preconceitos e discriminaçóes.

Ainda sobre as universidades públicas, cabe mencionar os estudos do professor Osvaldo Cerezer (2015), a respeito dos projetos pedagógicos dos cursos de graduaçáo em História da UFMT com sede em Cuiabá e no campus de Rondonópolis, incluindo também análises sobre a UNEMAT. Destacarei os dados sobre o processo de implementação da Lei no 11.645/2008 no entâo curso de História de ambas as universidades. Inicio com o Curso de Licenciatura em História da UFMT em Cuiabá. A respeito da graduação, Osvaldo Cerezer (2015, p. 152) aponta:

O curso foi criado em 1979, ofertando 30 vagas. Em 1985, o curso passou a ofertar o bacharelado de forma conjunta com o curso de licenciatura. O Curso de História faz parte do Instituto de Ciências Humanas e Sociais da UFMT. [...] O mesmo curso ofertou vagas em turmas especiais, criadas nos municípios de Juína, Sorriso e Nova Mutum, além de turmas de capacitação, por meio de convênio com a SEDUC/MT (Secretaria de Estado de Educação), destinada ao atendimento e aprimoramento da formação de professores da rede pública.

A UFMT, como vimos, possui ampla experiência em cursos de formação continuada. Com essa preocupação nas décadas de 1980/1990, a instituição "produziu cursos de Especialização sobre His- 
tória e Historiografia do Mato Grosso e um curso sobre a História da África Contemporânea" (CEREZER, 2015, p. 152). Passado um tempo, já em 2010, a matriz curricular foi reformulada e as mudanças flexibilizaram o currículo. No ano de 2010 entrou em vigência a Lei no $11.645 / 2008$, porém o curso de graduação em História não atendeu fortemente à legislação.

Observamos que dentre os documentos/decretos e leis citados pelo referido PPP não aparece nenhuma mençáo à Lei no $11.645 / 08$ que tornou obrigatório o estudo da história e cultura dos povos indígenas. Somente a Lei $\mathrm{n}^{\circ} 10.639 / 03$, que estabeleceu a obrigatoriedade do estudo da história africana e afro-brasileira, é citada pelo documento institucional.

[...] A reformulação do curso ocorrida em 2010, não contemplou, a nosso ver, nos componentes do currículo, objetos de estudos sobre a questão indígena. Salientamos que o disposto na Lei no $11.645 / 08$, abordagem considerada essencial para formação de novos professores de História, não faz parte do PPP do curso (CEREZER, 2015, p. 152-154).

No entanto, o pesquisador, ao analisar a ementa do curso de História, verifica que na disciplina "História do Brasil I, com 72 h/a (setenta e duas horas aula), o tema é restrito às discussóes relacionadas às sociedades ameríndias. A ementa sugere a reflexão crítica sobre a participação dos indígenas na formação da identidade nacional e às imagens destes nos manuais didáticos" (CEREZER, 2015, p. 155).

Podemos concluir que a temática dos povos indígenas, de algum modo, é abordada no curso, porém os estudos de Cerezer (2015) revelam-nos que mesmo com as reformulaçóes dos componentes curriculares a ementa menciona de maneira subjetiva e parcial a questáo indígena, o que náo contempla a Lei no 11.645/2008.

Já o curso de Licenciatura Plena em História da UFMT, campus de Rondonópolis, criado em 2004, em 2006 passou por uma reformula- 
ção gradativa. Osvaldo Cerezer (2015) analisou o Plano de Formação de História e constatou que a temática africana e afro-brasileira está inclusa nos currículos de licenciatura de História. O tema foi inserido como criação da disciplina obrigatória, História da África Negra, com 68 horas/aula. De acordo com Jesus (2009 apud CEREZER, 2015, p. 159), "a inclusão foi resultado da pressão do Movimento Negro que conseguiu 2.546 assinaturas pedindo a incorporação da disciplina no curso”.

Com relação à temática indígena, o tema ocorre por meio de disciplinas obrigatórias e não específicas, como a história do Brasil Colônia, história do Mato Grosso e história contemporânea. No entanto, a licenciatura oferece também disciplinas flexíveis (optativas) e seminários temáticos (CEREZER, 2015, p. 159). De maneira geral, podemos dizer que a questão indígena no curso de História no campus de Rondonópolis está em consonância com a graduação em História no campus de Cuiabá. As análises das ementas demonstram que mesmo após as reformulaçóes do currículo, com a Lei no 11.645 em vigência, o ensino de História e culturas indígenas é discutido predominantemente em disciplinas optativas.

Por último, analisemos o curso de licenciatura em História da UNEMAT, campus de Cáceres. A graduação foi criada "no ano de 1990/II por meio da autorizaçáo do Decreto Presidencial de 11 de setembro de 1992, publicada no Diário Oficial da Uniāo [...]. A criação do curso fazia parte do projeto de expansão da Fundação Estadual de Ensino Superior do Mato Grosso" (CEREZER, 2015, p. 162-163). Para o funcionamento do curso, ainda em 2009, foi necessário incluir uma disciplina voltada aos estudos da África e seus descendentes. Assim, o curso de História contemplava os estudos de história da África por meio de apenas uma disciplina optativa, denominada história da África e afrodescendentes no Brasil, com carga horária de 60 horas/ aula. Osvaldo Cerezer (2015, p. 163) explica que "o currículo do curso contemplava o disposto na Lei $\mathrm{n}^{\circ} 10.639 / 03$ de forma parcial, pois a disciplina tinha o caráter optativo e não era ofertada em todos os anos letivos dificultando o acesso de um número maior de acadêmicos aos estudos sobre a África”.

Sobre o ensino da temática dos povos nativos, Cerezer (2015, p. 163) evidencia que "o estudo sobre as questóes indígenas somente 
passou a fazer parte do currículo a partir das exigências realizadas pela Comissão de Verificação em 2009”. O pesquisador concluiu que a "incorporação curricular das temáticas africanas e indígenas, como disciplinas obrigatórias, foi efetivada a partir da recomendação da Comissão Verificadora in loco de 2009" (CEREZER, 2015, p. 166).

Após a inclusão da temática indígena no currículo, efetivada pela ação da referida comissão, as ementas disciplinares que compóem o Programa de História Indígena tiveram como objetivo "refletir sobre alguns estudos de diferentes abordagens relativas à história indígena do Brasil e Mato Grosso. Visando o encaminhamento reflexivo sobre as metodologias e aplicabilidades do ensino de história indígena em sala de aula" (CEREZER, 2015, p. 162).

No caso, o curso de História da UNEMAT de Cáceres, diferente das graduaçóes da UFMT aqui discutidas, abre outras possibilidades de abordagem da temática indígena, assim como a africana em disciplinas como história da América I, história do Brasil I e II e história do Mato Grosso I. Essas disciplinas possibilitam discutir os temas de maneira integrada, fazendo os estudantes refletirem sobre o contexto de dois segmentos sociais que ainda hoje sofrem historicamente com o preconceito, a discriminação e a exclusão histórica. De certa forma, creio ser relevante a participação dos docentes indígenas à frente do ensino de História nos cursos das universidades.

\section{UMA DÉCADA DA LEI N 11.645/2008: AVANÇOS E DESAFIOS}

Além de analisar os PPPs dos cursos de História, a conclusão de Osvaldo Cerezer foi baseada na análise das ementas disciplinares e seus impactos na formação de profissionais oriundos dos cursos de História nos três campi universitários.

Nos últimos anos as discussóes e os debates sobre a lei têm sido pauta de várias instituições, tais como as secretarias de estado e do município, as universidades, entre elas a UFMT e a UNEMAT, e também em cursos e encontros relacionados à temática indígena. Vale destacar que no Mato Grosso a presença indígena ganhou visibilidade quando 
as universidades criaram políticas de ações afirmativas atendendo às reivindicaçóes encaminhadas pelo CEEI-MT (MATO GROSSO, 2013). Mediante as demandas trazidas pelas lideranças indígenas por meio de seus representantes do colegiado da Organização de Professores Indígenas de Mato Grosso (OPRIMT) e do Instituto Indígena MAIWU de Estudos e Pesquisas de Mato Grosso, apresentou-se à reitoria a proposta de vagas para os estudantes indígenas, indicando vários cursos e priorizando a área da saúde.

Em tal contexto, em 2007 foi criado o Programa de Inclusão Indígena "Guerreiros da Caneta" (PROIND), cuja finalidade é promover o acesso dos estudantes indígenas de diferentes etnias aos cursos de graduação. Na UFMT, o programa está amparado pela Resolução do Conselho de Ensino, Pesquisa e Extensão da UFMT (CONSEPE) $n^{\circ} 131$, de 30 de outubro de 2017 que "dispóe sobre a adequação da Resolução do CONSEPE no 98, de 13 de novembro de 2012, que trata da adequação do Programa de Ação Afirmativa na UFMT à Lei no 13.409/2016" (MATO GROSSO, 2017). Portanto, as ações afirmativas são importantes para manter os indígenas nas universidades, uma vez que "não adianta trazer estudantes indígenas para estudar se não tem assistência, auxílio e alimentação", destaca Eric Timoteo Iwyrâkâ Kamikiawa (apud ALVES, 2018, p. 4).

As cotas são necessárias, na opinião de diferentes alunos indígenas universitários. Porém, outras ações também são indispensáveis, como o PROIND para mantê-los nas instituiçóes. Para Maria Elizandra Lopes Torekureuda, "a cota é válida, mas se observarmos existem poucos indígenas realmente da aldeia que conseguem entrar pela lei de cotas. Muitas coisas têm que ser mudadas para atender os estudantes indígenas que vêm da aldeia” (apud ALVES, 2018, p. 3).

A UNEMAT, por sua vez, criou no campus Barra do Bugres em 2001, o curso de licenciatura intercultural específico para contemplar a formação de professores indígenas no ensino superior. A graduação é oferecida a diferentes povos indígenas do Mato Grosso, como os Apiaká, Bakairi, Bororo, Chiquitano, etnias do Parque do Xingu, Karajá, Mebengôkre, Nambikwara, Paresí, Rikbaktsa, Terena, Xavante, Zoró e outros. Foi um momento histórico importante que marcou a formação de professores indígenas na Regiāo Centro-Oeste e no Brasil, pois a UNEMAT 
se destaca por seu pioneirismo como a primeira universidade fundadora de uma licenciatura indígena no país.

$\mathrm{Na}$ instituição existe a presença de políticas de ação afirmativa baseadas em sistemas de cotas sociais e raciais para o ingresso nos cursos de graduação. Trata-se do Programa de Integração e Inclusão Étnico-Racial (PIIER), criado em 2004 e implementado em 2005 com vagas reservadas para candidatos autodeclarados negros. Em 2013, o programa inseriu a ação afirmativa destinada a estudantes de escolas públicas e apenas em 2016 incluíram-se estudantes indígenas através do PIIER Indígena (UNEMAT, 2016).

Essas iniciativas no campo das açóes afirmativas resultam da agenda dos movimentos indígenas e suas organizaçóes sacramentadas desde o Congresso de Professores Indígenas do Brasil, realizado em Cuiabá entre os dias 17 e 21 de novembro de 1997. Cabe destacar que os eventos foram organizados e coordenados pelo CEEI-MT. Naquela época, lideranças e professores indígenas manifestavam o desejo de buscar no ensino superior, conhecimento e ferramentas para instrumentalizar lutas e garantir direitos.

A procura pelas histórias dos povos indígenas despertou interesses de diferentes setores da sociedade para conhecer o cotidiano das populaçóes. Pesquisadores de distintas universidades passaram a focar seus olhares no interior das aldeias. O intercâmbio entre aldeias e cidades foram fundamentais para que as populaçóes pudessem conhecer a cultura, os costumes e tradiçóes dos seus vizinhos munícipes. Para os povos indígenas é uma oportunidade de se relacionarem com a sociedade envolvente numa outra dimensão de humanidade e conhecimento.

O reconhecimento da pluralidade étnica pelos estados ainda é uma luta a ser travada, caminha em passos lentos, em agendas pontuais e depende da vontade dos gestores à frente das instituiçóes dos sistemas de ensino para que a formação continuada se consolide como política pública de Estado e não de governo (LUCIANO, 2006). A consolidação da Lei no 11.645/2008, nesse contexto, representa a reversão do modo de pensar, do agir e do olhar o outro despido de preconceito e rancores históricos. 
É preciso ressaltar que no caso do Mato Grosso, ainda que com o esforço de instâncias formadoras como o CEFAPRO, o Estado como responsável pelas políticas públicas ainda não assumiu, na integralidade, a diversidade como prática. São vários os problemas que a equipe encontra para efetivar açóes, tais como o aspecto financeiro, logístico e a carência de materiais didáticos relativos à questão indígena. A atenção dos gestores públicos para as realidades das populaçóes indígenas no estado surgiu a partir do momento que a presença indígena exigia respostas perante a discriminação instituída. As críticas foram denunciadas por meio do colegiado representativo, o CEEI. Como vimos, é nesse contexto que foi publicada a Resoluçáo Normativa no 001/2013 (MATO GROSSO, 2013).

No tocante às universidades, podemos perceber que o processo de implementação da Lei no $11.645 / 2008$ ainda está em aberto, pois a temática indígena é tratada de forma tangencial, a partir de disciplinas optativas ou por seminários temáticos. Os impactos na formação de professores são tímidos, não se chegou a uma decisão de quais formaçôes inicial e continuada serão as bases que fundamentaráo o combate ao racismo nas universidades. Nesse sentido, concordo com Cerezer (2015, p. 298) quando diz:

A constatação das limitações e resistências no interior dos Cursos de História investigados sobre o trato da problemática racial demonstra que apesar da inclusão tímida de disciplinas específicas sobre a história dos africanos, afro-brasileiros e indígenas e dos esforços solitários de formadores, o caminho a ser percorrido ainda é longo, instável e repleto de lutas a serem travadas e superadas.

Portanto, entendo que os avanços pontuais estão na criação da Lei $n^{\circ} 11.645 / 2008$ e na intencionalidade positiva dos envolvidos com a causa indígena. Com aqueles que lutam na busca do reconhecimento dos povos indígenas como sujeitos da história, por uma sociedade mais democrática e com justiça social. Nessa direção, Silva (2001, p. 120) ensina-nos: 
Se se quer ter a tolerância como objetivo a ser incorporado à mentalidade brasileira pela via da Educação, a formação continuada de professores das redes públicas e privadas e os cursos de licenciatura nas universidades devem acolher sistematicamente atividades voltadas à sensibilização para a alteridade e garantir o acesso dos professores e estudantes ao conhecimento acumulado sobre os grupos étnicos específicos e os povos indígenas no país.

Desse modo, os processos de resistência institucional e a herança eurocêntrica presente nos projetos pedagógicos dos cursos são grandes desafios para as universidades e para as mudanças sociais. Elas terão que enfrentar comportamentos, "como açóes, posturas e ideologias dos formadores de professores no trato das relações étnico-racionais" (CEREZER, 2015, p. 300).

\section{CONSIDERAÇÕES FINAIS}

Nesse artigo, busquei analisar a Lei no $11.645 / 2008$ a partir das medidas adotadas pela Secretaria do Estado de Educação e das universidades para atender à Resolução Normativa no 001/2013 (MATO GROSSO, 2013), que regulamenta a obrigatoriedade dos estudos acerca da História e culturas indígenas no estado do Mato Grosso. Nas leituras e observaçóes que fizemos de documentos, diretrizes, programas e projetos da SEDUC-MT, verificamos que a equipe encarregada de implementar a lei demonstra o desejo de concretizar as açóes planejadas. Além disso, as parcerias com diferentes instituiçóes (entre elas as universidades) são vistas, em um futuro promissor, como modo gradativo de consolidar a temática dos povos indígenas na pauta da educação básica do estado. No entanto, ainda há resistências e ausência de uma política consistente de formação continuada para professores desenvolverem a temática e o cumprimento da lei.

Apesar de existirem várias documentações, diretrizes e propostas de cunho orientativo para as escolas públicas, não há o acompanhamento desse processo. Os multiplicadores das açóes for- 
mativas ficam comprometidos devido ao contingenciamento dos recursos; alguns setores estão praticamente escassos de verba e materiais pedagógicos. Essa tem sido a reclamação frequente dos profissionais envolvidos na implementação da Resolução Normativa no 001/2013 (MATO GROSSO, 2013).

As universidades precisam atuar junto à sociedade, promovendo uma formação acadêmica que nos permita vislumbrar o reconhecimento dos povos indígenas como contribuintes para a formação do povo brasileiro. Um dos caminhos para tornar referida dimensão possível é reconhecer e acolher os PPPs dos cursos de licenciatura em História, atendendo à Lei no 11.645/2008. As duas instituiçóes aqui analisadas atendem aos estudantes indígenas nos diferentes cursos, mas se contradizem quando negam o que preconiza a lei. Entendo que precisam estabelecer um novo direcionamento na organização curricular dos cursos, pois são eles que formarão os docentes indígenas e não indígenas.

É necessário incluir conhecimentos e conteúdos relacionados à diversidade sociocultural e linguística dos povos indígenas, possibilitando, desse modo, que os professores adquiram novas concepçóes filosóficas, políticas e pedagógicas, conheçam e acolham as culturas indígenas (CARNEIRO DA CUNHA, 2009). Nesse sentido, uma das falhas que verifico é a ausência de materiais didáticos que possam contribuir para a qualificação tanto na formação inicial quanto no que se refere à formação continuada.

Como bem ressalta Gersem Baniwa (LUCIANO, 2006), "falar hoje de índios no Brasil significa falar de uma diversidade de povos, habitantes originários das terras conhecidas na atualidade como continente americano. São povos que já habitavam há milhares de anos essas terras, muito antes da invasão europeia” (LUCIANO, 2006, p. 27).

Sendo assim, os cursos de licenciatura em História, suas disciplinas e ementas específicas sobre a temática indígena necessitam dar mais atenção e consistência à história dos povos indígenas, pois entendo que são sobreviventes e resistentes à colonização, estão no processo de recuperação da memória, da história e buscam consolidar um espaço digno na vida cultural do país (CARNEIRO DA CUNHA, 2009; LUCIANO, 2006). 
Trazer a temática indígena para os espaços de formação das universidades é uma forma de discutir e debater sobre os processos da História do Brasil e do Mato Grosso. Igualmente, reconhecer o indígena como um dos pilares da formação da sociedade mato-grossense e brasileira como protagonista da sua história no mundo contemporâneo; imperativo necessário para entender o universo indígena. Portanto, após dez anos da Lei $n^{\circ} 11.645 / 2008$ não há como celebrar, mas apenas apoiar todas as iniciativas daqueles engajados na luta por uma educação mais diversa e representativa das culturas indígenas.

\section{REFERÊNCIAS}

ALVES, J. Indígenas buscam conhecimentos para auxiliar nas aldeias. Especial Hipernotícias, Cuiabá, v. 1, 2018. Disponível em: shttp://www.hipernoticias. com.br/cidades/>. Acesso em: 3 ago. 2018.

BRASIL. Constituição da República Federativa do Brasil. Brasília: Senado Federal, 1988.

BRASIL. Diretrizes Curriculares Nacionais para a Educação das Relaçôes Étnico-Raciais e para o Ensino da História e Cultura Afro-brasileira e Africana. Brasília: MEC, 2004. Disponível em: <http://portal.inep.gov.br/informacaoda-publicacao/-/asset publisher/6JYIsGMAMkW1/document/id/488171>. Acesso em: 9 ago. 2018.

BRASIL. Lei $\mathrm{n}^{\circ}$ 11.645. Altera a Lei ${ }^{\circ}$ 9.394, de 20 de dezembro de 1996, modificada pela Lei $\mathrm{n}^{\circ} 10.639$, de 9 de janeiro de 2003, que estabelece as diretrizes e bases da educaçáo nacional, para incluir no currículo oficial da rede de ensino a obrigatoriedade da temática "História e Cultura AfroBrasileira e Indígena". Diário Oficial da República Federativa do Brasil, Brasília, 2008.

CARNEIRO DA CUNHA, M. Cultura com aspas e outros ensaios. São Paulo: Cosac Naify, 2009.

CEREZER. O. M. Diretrizes Curriculares para o ensino de história e cultura afrobrasileira e indígena: implementação e impactos na formação, saberes e práticas de professores de história iniciantes (Mato Grosso, Brasil). 328f. Tese (Doutorado em Educação) - Programa de Pós-Graduação em Educação, Universidade Federal de Uberaba, Uberaba, 2015. 
FREIRE, J. R. B. Rio Babel. A história das línguas na Amazônia. Rio de Janeiro: Eduerj, 2011.

LOURENÇO, S. R. (Coord.). Projeto Curso de Formação: métodos e práticas educativas em Direitos Humanos: Relação Étnico-Raciais, Diversidade Cultural e Religiosa, Relação de Gênero e Diversidade Sexual. Cuiabá: UFMT, 2017a. Disponível em: <http://sistemas.ufmt.br/ufmt.siex/Comum/

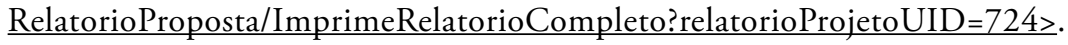
Acesso em: 3 maio 2018.

LOURENÇO, S. R. Projeto Curso de Formação Intercâmbio Educacional e Intercultural - a Lei 11645/08 em suas dimensóes pedagógicas. Cuiabá: UFMT, 2017b. Disponível em: <https://sistemas.ufmt.br/ufmt.siex/Projeto/ Detalhes? projetoUID=3423>. Acesso em: 8 ago. 2018.

LUCIANO, G.S. $O$ indio brasileiro: o que você precisa saber sobre os povos indígenas no Brasil de hoje. Brasília: SECADI/LACED, 2006.

MATO GROSSO. Resolução Normativa no 001/2013-CEE/MT. Dispõe sobre a oferta obrigatória da Educação das Relaçôes Étnicas e Raciais e do estudo da História e Cultura Afro-Brasileira, Africana e Indígena, nos estabelecimentos de Educação Básica, públicos e privados do Sistema Estadual de Ensino, e dá outras providências. Diário Oficial de Mato Grosso, Mato Grosso, p. 31, 2013.

MATO GROSSO. Universidade Federal de Mato Grosso. Resolução CONSEPE $n^{\circ}$ 131, de 30 de outubro de 2017. Dispóe sobre a adequação da Resoluçáo CONSEPE no 98, de 13 de novembro de 2012, que trata da adequação do Programa de Ação Afirmativa na UFMT, à Lei no 13.409/2016. Mato Grosso, 2017.

ORGANIZAÇÃO INTERNACIONAL DO TRABALHO (OIT). Convenção no 169 sobre Povos Indigenas e Tribais. Genebra: OIT, 1989. Disponível em: $\leq$ http://portal.iphan.gov.br/uploads/ckfinder/arquivos/Convencao 169 OIT. pdf>. Acesso em: 10 jul. 2018.

SECRETARIA DE ESTADO DE EDUCAÇÃO DO MATO GROSSO (SEDUC). Orientaçóes Curriculares das Diversidades Educacionais. Cuiabá: Defanti, 2010.

SECRETARIA DE ESTADO DE EDUCAÇÃO DO MATO GROSSO (SEDUC). Projeto de Monitoramento do Cumprimento das Leis Federais $n^{o}$ 10.639/03 e 11.645/08. Secretaria de Estado de Educaçáo do Mato Grosso. Cuiabá, 2017. 
SILVA, A.L. Educação para a Tolerância e Povos Indígenas. In: GRUPIONI, L.D.; VIDAL, L.B.; FISCHMANN, R. (orgs.) Povos indígenas e tolerância: construindo práticas de respeito e solidariedade. São Paulo: Edusp, 2001. p. $120-132$.

UNIVERSIDADE DO ESTADO DE MATO GROSSO (UNEMAT). Resolução no 071/2016 - CONEPE. Cáceres, p. 1-3, 2016.

\section{NOTAS}

1. Na situação histórico-política e social do estado do Mato Grosso, a constituição dos municípios ocorreu sob um processo de embates de extrema violência que ainda estão presentes nas memórias dos povos indígenas e da população local.

2. Num contingente de 720 escolas da rede pública cujo Conselho Indígena acompanhou na capital Cuiabá e em Várgea Grande, algumas instituiçóes realizam atividades nas quais a presença indígena é convidada a ministrar palestras, contar histórias e realizar pinturas corporais.

3. O Conselho Estadual de Educação Escolar Indígena (CEEI-MT) de Mato Grosso é uma instância de colegiado composto por 38 conselheiros, sendo 26 membros indígenas professores e lideranças oriundas de várias regióes do estado, fazem parte também organizaçóes não governamentais (ONGs) indígenas, indigenistas e instituiçóes governamentais. $\mathrm{O}$ conselho tem como finalidade monitorar e fiscalizar as políticas educacionais dos governos, respaldado pela Convenção n ${ }^{\circ} 169$ de 1989 (OIT, 1989). Para implementar a regulamentação foram realizadas cinco audiências públicas nos seguintes municípios de Mato Grosso: Poconé, Vila Bela da Santíssima Trindade, Cáceres e Cuiabá. A ação do colegiado foi possível através da parceria com o Conselho Estadual de Educação (CEE-MT), responsável pela divulgação normativa.

4. O Conselho Estadual de Educação (CEE-MT), por meio da Comissão de Direitos Humanos, protagonizou a criação do grupo de trabalho para regulamentar as novas leis $\mathrm{n}^{\circ} 10.639 / 2003$ e $^{\circ} 11.645 / 2008$, juntamente com o Conselho Estadual de Educação Indígena (CEEI-MT).

5. Tese intitulada Diretrizes Curriculares para o Ensino de História e Cultura Afro-Brasileira e Indígena: implementação e impactos na formação, saberes e práticas de professores de História iniciantes (CEREZER, 2015). O cenário compreende as três universidades públicas, UNEMAT, UFMT e UFMT - Campus Rondonópolis. A pesquisa analisa os impactos na formação inicial de professores de História, estendendo o estudo para o ensino da temática em escolas públicas e privadas.

6. Superintendência de Políticas de Diversidades Educacionais, setor parte da Secretaria do Estado que atende às temáticas da diversidade. 
7. O Centro de Formação e Atualização dos Profissionais da Educação (CEFAPRO) é um centro de formação vinculado à Secretaria de Estado de Educação, Esporte e Lazer (SEDUC) que atua na formação continuada dos profissionais da educação.

8. O projeto é organizado pelo Programa de Pós-Graduação em Antropologia Social (PPGAS-UFMT) com apoio da Secretaria de Estado de Educação, Esporte e Lazer (SEDUC-MT) e da Superintendência de Diversidades Educacionais através da Coordenadoria de Diversidade Educacional (SEDUC-CDE).

Recebido em 6 de fevereiro de 2019.

Aprovado em 9 setembro de 2019. 